\title{
Erros e equilibração em psicologia genética
}

\author{
Sávio Silveira de Queiroz \\ Letícia Pires Dias \\ Josana Deriz Chagas \\ Patrícia dos Santos Nepomoceno
}

\begin{abstract}
Resumo
Os erros presentes nas tarefas de um sujeito construtor de conhecimento são importantes porque, ao se constituírem como observáveis, favorecem os processos de equilibração. Para o pesquisador, clínico ou professor, a observação construtivista dos erros pode garantir uma objetividade mínima nos processos de diagnóstico e intervenção. Nossa intenção neste trabalho de revisão teórica (ilustrado por comentários sobre um estudo de caso) é caracterizar o erro como parte inerente à atividade do sujeito construtor que, quando colocado a solucionar um problema, aproveita-se desse erro para promover a abertura de novos possíveis e, em seguida, dialeticamente, reduzi-los a um único possível, garantindo assim sua condição de necessário. Tentamos atualizar a caracterização dos erros como parte do processo de aprendizagem e reveladores da lógica infantil, criticando posições que os consideram meramente indícios de incapacidades e dificuldades em resolver tarefas.

Palavras-chave: Psicologia Genética, teoria da equilibração, Piaget.
\end{abstract}

\section{Errors and equilibrium in the genetic psychology}

\begin{abstract}
The errors present in the tasks of a subject builder of knowledge are important because, they are observable and promote the process of balancing. For the researcher, clinician or teacher, the observation of constructivist errors can guarantee a minimum objectivity in the process of diagnosis and intervention. Our intention in this review of theoretical work is to characterize the error inherent in the activity as part of the subject construction that, when placed to resolve a problem, taking advantage of this error is to promote the opening of new possibilities. We try to update the characterization of errors as part of the learning process and highlight the logic of children. We criticiz the positions that consider the error as evidence of disability and difficulties in solving tasks.
\end{abstract}

Keywords: Genetic Psychology, equilibration theory, Piaget.

\section{Errores y equilibrio en psicología genética}

\section{Resumen}

Los errores presentes en las tareas de un sujeto constructor de conocimiento son importantes porque, al constituirse observables, favorecen los procesos de equilibrio. Para el investigador, clínico o profesor, la observación constructivista de los errores puede garantizar una objetividad mínima en los procesos de diagnóstico e intervención. Nuestra intención en este trabajo de revisión teórica (ilustrado por comentarios sobre un estudio de caso) es caracterizar el error como parte inherente a la actividad del sujeto constructor que, cuando llamado a solucionar un problema, se aprovecha del error para promover la apertura de nuevos posibles y, en seguida, dialécticamente reducirlos a un único posible, garantizando así su condición de necesario. Intentamos actualizar la caracterización de los errores como parte del proceso de aprendizaje y como reveladores de la lógica infantil, criticando posiciones que los consideran meros indicios de incapacidades y dificultades al resolver tareas.

Palabras Clave: Psicología Genética, teoría de la equilibración, Piaget. 


\section{Introdução}

A Psicologia Genética constituiu-se como método genético criado por Piaget com o intuito de investigar epistemologicamente as mudanças no funcionamento cognitivo do indivíduo, do nascimento à adolescência (Piaget, 1978). Os erros presentes em qualquer desenvolvimento de tarefas de um indivíduo considerado construtor de um conhecimento são importantes porque, ao se constituírem como observáveis, tornam-se um problema para o próprio indivíduo, favorecendo processos de equilibração majorante na medida em que a relação que estabelece com os erros começa a se modificar.

Piaget (1976) afirma que a equilibração é um processo regulador o qual permite que novas experiências e elementos exteriores sejam, com sucesso, incorporados às estruturas mentais e cognitivas pelas quais os indivíduos intelectualmente se adaptam e organizam o meio. No contexto do desenvolvimento cognitivo, configura-se como processo de passagem do desequilíbrio para o equilíbrio, conceitos fundamentais para essa teoria. Os organismos funcionam de modo a atingirem ou procurarem manter um estado de equilíbrio interno que os permita sobreviver em diversos ambientes. Para isso, vários elementos orgânicos organizam-se de forma a promover o desenvolvimento ou manter o funcionamento harmônico geral. Se um dos elementos do sistema entra em desacordo com os demais, processos internos atuam com vistas à retomada do estado de equilíbrio anterior. Portanto, a equilibração consiste em um processo de organização das estruturas cognitivas num sistema coerente, interdependente, ou seja, há uma dependência recíproca entre as partes e o todo do sistema cognitivo, possibilitando ao indivíduo uma adaptação à realidade.

O desequilíbrio pode ser considerado como um estado de conflito cognitivo, o qual ocorre quando expectativas ou predições não são confirmadas pela experiência, ou em virtude de objetos de conhecimento inassimiláveis pelos esquemas à disposição. Ele desempenha um importante papel motivacional ao levar o indivíduo a se mobilizar para ultrapassar seu nível cognitivo atual. Nesse caso, busca-se o equilíbrio, que pode ser visto como um estado de "balanço" cognitivo a ser alcançado por meio de regulações, as quais se constituem como um mecanismo de autocorreção dos erros, relacionando um novo elemento aos esquemas já construídos previamente.

Na perspectiva do pesquisador, clínico ou professor, a observação dos erros pode garantir uma objetividade nos procedimentos de diagnóstico e intervenção. Alguns autores buscaram compreender a importância do erro, assim como suas contribuições, para os contextos clínicos ou escolares. Segundo Correia (2005), a Psicologia Genética provocou mudanças no contexto didático, que assumiu uma nova postura sobre a perspectiva dos erros, passando a aproveitá-los como recurso pedagógico no processo de ensino-aprendizagem. O processo de aprender envolve tentativas, hipóteses e levantamento de suposições. Evidentemente, as pessoas erram em suas tentativas de aprender. No entanto, sob essa ótica, os erros funcionarão como elementos formadores da construção do conhecimento, na medida em que se incentive e favoreça a reflexão sobre eles, como forma de se promover suas superações.

Kistemann Jr. (2004) investigou como a avaliação praticada no ensino de Matemática, nas suas mais variadas formas, tem auxiliado o professor a regular a aprendizagem por meio dos erros cometidos pelos alunos e também verificou qual o efetivo papel do erro na construção do conhecimento matemático. A análise dos resultados de sua pesquisa indicou que a avaliação é utilizada prioritariamente para servir ao professor a fim de efetuar verificação da aprendizagem. A verificação dos erros seria utilizada para replanejar o ensino dos conteúdos, havendo pouca preocupação em torná-los observáveis, com funcionalidade pedagógica, ao aluno. Além disso, os professores apresentaram a ideia de erro como um fator negativo, que deve ser evitado, sem demonstrarem preocupação com sua gênese.

Cury (2004) apresenta algumas ideias sobre a análise de erros e sua utilização na educação matemática por meio de esquema para uso dos erros; apresenta também considerações sobre avaliação e uma retrospectiva de pesquisas realizadas no século passado em que cita a importância do construtivismo como ferramenta para a aprendizagem. Davis e Espósito (1998) também buscam auxiliar a reflexão a respeito da passagem da teoria de desenvolvimento cognitivo de Piaget a uma teoria de aprendizagem escolar por meio de discussão das implicações pedagógicas dessa abordagem, notadamente a respeito da função atribuída ao erro.

Neste artigo, nossa intenção é caracterizar o erro como parte inerente à atividade do indivíduo construtor que, quando colocado frente a um problema, aproveita-se desse erro para promover a abertura de novos possíveis e, em seguida, dialeticamente, reduzi-los a um único possível, o qual garante a sua condição de necessário. Evidentemente que essa forma de compreender o erro não se constitui como uma novidade, mas o problema reside exatamente em se encontrar melhores modos de convencimento do leitor, tarefa que pode ser mais bem esclarecida segundo a análise que fizemos sobre alguns textos escolhidos para abordar o problema que aqui estabelecemos.

Piaget, citado por Sisto (1996), relatou uma experiência sobre os mecanismos de construção da novidade, ou sobre a criatividade, analisando dados apresentados pelas crianças que, ao desenvolverem uma dada tarefa, defrontaram-se com conteúdos novos que lhes foram apresentados em um processo de ensino-aprendizagem sobre o conteúdo temático que denominaremos como "equidistância". Nesse experimento, solicitou-se à criança que colocasse alguns objetos a uma mesma distância de um ponto de referência. Disponibilizaram-se, inicialmente, apenas dois elementos; em seguida, cinco; depois, sete e, por fim, doze elementos. Após a resposta de cada participante, solicitava-se que apontasse outra possibilidade configurativa para o arranjo apresentado, e assim sucessivamente, até que se esgotassem declaradamente todas as possibilidades de rearranjo do conjunto. 
Piaget classificou três grandes níveis de construção da novidade: 1) estágio dos possíveis analógicos; 2) estado dos copossíveis; e 3) estágio dos copossíveis quaisquer. As crianças analógicas apresentavam várias soluções que, para elas, estavam "o mesmo tanto de longe", mas que, do ponto de vista lógico e métrico, não poderiam ser consideradas corretas. No estágio de copossíveis, a criança apresentava respostas corretas (um círculo ou semicírculo ao redor do ponto de referência) como apenas uma entre as respostas possíveis, ainda não a distinguindo das outras soluções que propunha. No entanto, para o participante no estágio dos copossíveis quaisquer, existia uma única possibilidade correta, que era o círculo ou semicírculo. Os possíveis que apresentavam consistiam no procedimento de se aumentar ou diminuir o raio ou diâmetro da figura. Com essa experiência, foi possível observar que o ser cognoscente é capaz de criar o possível correto mesmo antes de saber que ele é correto; a organização lógica das alternativas era, portanto, um procedimento posterior. Dessa forma, para o construtivismo, o que são considerados erros nada mais são do que elementos que ainda não foram organizados de forma lógica em um sistema cognitivo.

Os erros podem ser causa de desequilíbrio cognitivo, mas, por outro lado, comparecem como essenciais para a organização dos procedimentos que conduzem à equilibração majorante. Desde a experiência inaugural de Piaget (1981) com o Jogo da Senha, erros são considerados fundamentais para elaboração de níveis de compreensão, os quais serão oportunamente conceituados após algumas considerações iniciais.

Um dos objetivos da epistemologia genética ${ }^{1}$ é definir estágios de desenvolvimento situando limites à realização de ações que exigiriam estruturas mais complexas. Esses limites são definidos basicamente pela presença de erros que, ao impossibilitarem a elaboração das hipóteses necessárias, impedem a conclusão ou compreensão plena das ações em exame. Neste sentido, o erro provoca pelo menos uma questão fundamental: ele aparece por um simples acaso em meio aos procedimentos ou abriga uma concepção lógica no contexto da resolução de um problema?

A resposta exige considerável análise teórica. Se considerarmos a aquisição de conhecimentos como processo genético efetuado por um indivíduo ativo e construtor, deveremos também considerar a função dos erros para além da perspectiva puramente estrutural, na medida em que a explicação dos mecanismos formadores das estruturas passam a ocupar posição de destaque nessa nova visão, denominada por Inhelder \& Piaget $(1979)^{2}$ como "abordagem microgenética". Essa abordagem propõe um procedimento experimental, cuja característica definidora é a de permitir observar e analisar em pormenores o desenvolvimento das descobertas que a criança faz ao tentar resolver um problema (Ribeiro, 2001). Nela, o erro é considerado como mecanismo inerente ao desenvolvimento de uma lógica

\footnotetext{
1 Estudo da gênese do conhecimento.

2 Barbël Inhelder \& Jean Piaget. Stratégies VIII - Procédure et structure.
}

necessária à aquisição de conhecimentos sem, contudo, desprezar-se o seu papel determinante na definição dos esquemas estruturais.

Casávola (1988) identificam a teoria da equilibração como adequada para delinear a fonte dos erros e dos mecanismos que atuam no sentido de sua ultrapassagem. A teoria da equilibração pressupõe constante inter-relação entre os processos de assimilação e de acomodação inerentes aos esquemas de ação. Para ele, "de um modo geral, a fonte dos erros reside nos desequilíbrios do funcionamento assimilador dos esquemas de ação" (p.34). Queiroz (1995) amplia essa discussão relacionando os erros com aspectos do desenvolvimento e aprendizagem:

\begin{abstract}
A tendência apontada pela teoria é a de que existe uma compensação progressiva dos desequilíbrios no sentido de um aumento do equilíbrio. Os limites da compreensão e da capacidade de resolução de tarefas são, ao mesmo tempo, fixados pela estrutura e determinados pelos procedimentos envolvidos na ação. Tais procedimentos implicam em elaboração de hipóteses, planejamento estratégico das ações e na adoção de alternativas que nem sempre levam ao êxito, mas que sempre permitem correções à medida que os erros tornam-se observáveis, o que, por sua vez, provoca um novo movimento de equilibração sempre dependente das condições estruturais limitadoras. (p. 53).
\end{abstract}

Apenas no sentido didático, Macedo $(1994)^{3}$ considera a questão do erro separadamente para o adulto ("perspectiva formal") e para a criança ("perspectiva natural"). Na perspectiva do adulto, "o errado se opõe ao certo, que é valorizado como verdadeiro ou bom" (p. 64), ou seja, espera-se que a busca pelo absolutamente certo seja socialmente muito valorizada. Posto assim, o erro é sentido com muita culpa e desgaste emocional, como algo que devemos evitar. Mas, objetiva e paradoxalmente, a complacência frente ao erro também pode ser facilmente observada. Já em uma perspectiva natural, o erro é uma parte intrínseca do processo de conhecimento, ele se faz necessário para se chegar ao resultado que se quer alcançar. Com a observação dos erros, é possível verificar quais aspectos que devem ser mantidos e quais devem ser corrigidos para se chegar ao resultado pretendido.

O autor verifica a influência do pré-formismo (ou inatismo) e do empirismo em nossa civilização. Pelo pré-formismo, aparece a necessidade do conhecimento expresso pela revelação de algo perfeito e que é intrínseco a nossa existência. Argumenta sobre a revelação platônica pela qual a ideia pré-formista torna as atitudes complacentes para com o erro; afinal, por meio desse modelo, já nascemos dotados de princípios racionais. Argumenta também sobre a transmissão aristotélica, pela qual o princípio empirista, regente dessa transmissão, é muito rigoroso para com o erro, na medida em que, de acordo com esse modelo, somos indivíduos com extrema plasticidade, moldados pela nossa experiência. Para

3 Publicado originalmente em: Coletânea de textos de Psicologia, Volume I, Psicologia da Educação (1990, pp. 345-362). 
Macedo, assim como no construtivismo, "a natureza não é complacente conosco. E, também, não é rigorosa. Ela é o que é." (p.67). O erro no construtivismo aparece, então, como uma terceira via, alternativa ao empirismo e ao pré-formismo, um meio-termo entre a complacência e o rigor.

No construtivismo, o erro é possível, ou até necessário, isto é, faz parte dos processos cognitivos. Assim, "a perspectiva construtivista da criança é a da criação: não é a da transmissão, nem a da revelação. Algo não está dado, terá que ser construído" (Macedo, 1994, p.69). E, para apresentar uma noção mais propriamente psicológica do erro, utilizamos novamente o texto de Macedo (1994), o qual nos permite inferir ou antecipar uma possivel relação entre os famosos níveis das provas operatórias de Piaget (1986) e o modo de lidar com os erros. Aproveitamos essa relação para justamente anunciar a constituição dos níveis de compreensão sobre o erro, tal como aceito atualmente pela Psicologia Genética.

No nível I, não há erro em uma perspectiva consciente; o erro é recalcado e as respostas contraditórias não causam conflito ou problema para as crianças. As tentativas de denunciá-lo são inoperantes.

No nível II, o erro aparece como um problema. Depois de tê-lo cometido, a criança o reconhece, apesar de já ser tarde. Além disso, as soluções ocorrem por ensaio e erro, por tentativas. A interferência exterior do adulto ou de outra criança já surte mais efeito, no sentido de problematizar a situação. Mas, ainda é uma perturbação exterior ao sistema cognitivo da criança. As iniciativas exteriores problematizam o erro. Ele instala-se como uma contradição que exige superação.

No nível III, o erro é superado enquanto problema. A criança pode antecipá-lo ou anulá-lo, ou seja, já dispõe de meios, dentro do seu sistema, para pesquisá-lo. Os erros anteriores são evitados nas ações seguintes. Há pré-correção do erro, há antecipação interior ao sistema. O sujeito adquire certa autonomia. (p.77).

Para falar em um sentido próprio da pedagogia, aproveitamos o destaque efetuado por Davis e Espósito (1990) sobre dois aspectos que compõem a estratégia utilizada pelo indivíduo na solução de uma tarefa: a compreensão do problema e os procedimentos para resolvê-lo. O nível estrutural da criança limita o conjunto de "possíveis" que podem conduzir ao êxito. Cabe ao professor 'construtivista' provocar novos desequilíbrios pelo uso de novas situações problemas, de modo a permitir a construção de novas estruturas. Argumentam sobre o significado da ocorrência do erro para o aluno e para o professor supondo três alternativas possíveis:

1) A criança possui a estrutura de pensamento necessária à solução da tarefa, mas selecionou procedimentos inadequados para tal;
2) A criança errou porque a estrutura de pensamento que possui não é suficiente para solucionar a tarefa (...) tais erros são construtivos porque sinalizam a formação de novas estruturas, a gênese de novas construções cognitivas;

3) A criança errou porque não possui a estrutura de pensamento necessária à solução da tarefa, de onde decorre uma impossibilidade de compreender o que the é solicitado. (p.74).

Esses autores entendem que, nesse contexto, a postura de experimentação deva conter estratégias de ação planejadas pelas quais os erros devem ser reconhecidos, tanto pelo professor quanto pelo aluno, como fazendo parte dessas mesmas estratégias, o que mudaria radicalmente os objetivos tradicionais de avaliação. Vinh-Bang (1990) propõe melhorias na prática pedagógica em geral com uma "análise da natureza dos insucessos", em que a percepção, a análise e a explicação dos erros possam contribuir para a aquisição de conhecimentos. A sistematização de erros possíveis e o seu conhecimento por parte do professor é, no seu entender, uma providência necessária para que se alterem as práticas pedagógicas visando ao melhor aproveitamento do erro.

Casávola (1988) nos mostram, ainda, que houve mudança de caracterização do erro desde que a Psicologia Genética pôde se constituir como teoria científica. "Os erros deixaram de ser somente indícios de dificuldades ou incapacidades e passaram a ser reveladores de uma lógica infantil irredutível à lógica dos adultos" (p. 33). Considerando-se, então, o erro sob uma perspectiva que é a do construtivismo, temo-lo sob dois aspectos: 1) erro procedimental e 2) erro sistemático. O erro procedimental é aquele que pode possibilitar ao indivíduo que o percebe obter certo avanço estrutural em direção ao equilíbrio majorante, posto que se manifesta na invenção e na descoberta e possui o poder de testemunhar a "abertura do pensamento para novos possíveis". Tendemos a considerar apenas o erro procedimental como sendo de importância e interesse para o estudo microgenético, quando, no entanto, o erro sistemático também deve ser foco de nossas atenções, posto que, enquanto o erro procedimental demarca a impossibilidade apenas momentânea no fazer do indivíduo, o erro sistemático denuncia uma etapa em que, ou não se torna possível a sua ultrapassagem, ou, no mínimo, a mesma é realizada sob intensa dificuldade cognitiva e instabilidade emocional. Por muito tempo, a Psicologia e a Epistemologia Genéticas, a par de possuírem o instrumental e a teoria necessária para análises e intervenções sobre o erro procedimental, normalmente relevavam por demais a ocorrência do erro sistemático ao caracterizá-lo como uma ocorrência inerente ao desenvolvimento estrutural sincrônico do indivíduo, algo natural e inevitável.

A título de exemplificação, imaginemos uma investigação realizada pela primeira vez com determinado jogo sobre um indivíduo que também jamais o tenha jogado. Após o período de aprendizagem das regras, durante as partidas realizadas, na primeira vez em que um determinado tipo de 
erro aparecer, será considerado como erro procedimental. Quando ocorrer novamente, nas jogadas subsequentes e ainda que em outra partida, será classificado como erro sistemático desde que não leve o seu praticante a qualquer tipo de equilibração majorante.

Macedo e cols. (2003) analisaram, na perspectiva construtivista de Piaget, como crianças resolviam e compreendiam problemas relativos a um jogo de Senha e apresentaram formas de intervenção face às respostas dos indivíduos e aos critérios propostos para a análise das respostas. Os autores relatam que, dependendo do tipo de erro, há uma forma de intervenção diferente, adequada para a necessidade do indivíduo e adaptada a sua compreensão da situação. Em outras palavras, se a criança produz uma resposta considerada insuficiente para resolver o problema proposto e também apresenta uma quantidade de erros que a classificam no nível I, é necessário um trabalho de intervenção que possa ajudá-la a perceber a incompletude ou insuficiência do que está produzindo (realizando), mesmo que ainda não possa superar seus erros. Seria inadequado propor ou esperar que já pudesse corrigi-los, ou, pior ainda, antecipá-los (compreendê-los). No caso de produções de nível II, o momento é de desequilíbrio em relação ao sistema, ou seja, a criança já começa a perceber erros, embora não seja capaz de superá-los sozinha. Retomar uma partida e analisar as decisões tomadas pode ser um bom recurso de intervenção para essas crianças. Ao se confrontar com seus erros, pode compreendê-los e evitá-los em outras partidas. No nível III, as respostas das crianças expressam uma síntese entre o realizar e o compreender. Essa síntese não lhes garante acertar sempre, daí a importância do valor que deve ser atribuído às intervenções e ao diálogo com as crianças após jogar e resolver situações-problema.

Para exemplificar o que foi discutido até agora, foi escolhido um estudo de caso componente de tese de doutorado de Queiroz (2000) que, dentre outros temas, objetivou a análise dos erros em suas relações com a equilibração. A metodologia foi aplicada em três estudantes que apresentavam dificuldades de aprendizagem em relação ao conteúdo programático geral da escola ou reiterações de comportamentos inadequados. Utilizaram-se quatro modalidades do Jogo da Senha (03 e 04 sinais), sendo duas em modelo de papel impresso (P3 e P4) e duas em jogo industrializado (T3 e T4). Adotou-se o Método Clínico, a partir da observação das características dos níveis de desenvolvimento e dos erros observados, com perguntas de exploração das regras, de justificação das estratégias e também de controle como forma de contraprova das respostas das crianças. Os dados foram tratados por análise microgenética dos procedimentos ao se examinar cada jogada efetuada pelos participantes da pesquisa, focalizando suas condutas e dinâmica de raciocínio utilizada. A principal conclusão em relação aos erros é a de que erros sistemáticos estão vinculados a manifestações da afetividade e sustentam desequilíbrios dificilmente reconhecidos pelos indivíduos.

A importância do estudo dos erros nessa tese se deve ao fato de que, enquanto os erros procedimentais são amplamente pesquisados pela Psicologia Genética, os erros sistemáticos são simplesmente e normalmente creditados às dificuldades estruturais que limitam os poderes do indivíduo. Exigia-se, pois, uma investigação que ultrapassasse as explicações baseadas nas 'dificuldades estruturais' que supostamente engendram esse tipo de erro. Esse contexto teórico possibilitou análises baseadas no conteúdo declarativo dos indivíduos, no estudo dos erros apurados, nos tipos de condutas e no exame das características de níveis de desenvolvimento encontradas, sendo que, sempre que possível, tais análises foram tratadas em suas relações de dependência umas com as outras.

Antes de explanar sobre o estudo de caso, é importante afirmar que o jogo da senha é conhecido mundialmente pelo nome comercial "MasterMind ${ }^{\mathrm{TM}}$ ". Ele aparece na literatura como objeto de investigação na construção de possíveis e necessários a partir dos trabalhos de Piaget (1986) com a colaboração de Vauclair e Maurbach em que sistematizaram a utilização do jogo nesta linha de pesquisa e deram-lhe a seguinte descrição:

Com efeito, 3 pequenos animais (um cavalo $C$, um coelho L e uma galinha $G$ ) ou 4 (mais um porco $P$ ) são escondidos sob uma tela e arrumados em uma ordem invariante. A criança dispõe de uma coleção dos mesmos objetos e pedese que ela os coloque na mesma ordem. A única informação que ela recebe em resposta aos ensaios consiste em indicar o número de posições certas que ela obteve sem o saber: para isso coloca-se em prolongamento desta série I um número de bolinhas amarelas equivalente ao número de êxitos: portanto de 0 a 3 ou 4 bolas, mas sem lhes dizer onde situa-se a correspondência exata. O sujeito constrói então uma nova série II colocada sob a primeira I, e novamente bolinhas são colocadas em função das posições iguais às do código escondido. O sujeito continua assim com as séries III, IV, etc., que permanecem sob as precedentes e é através dessas informações incompletas, mas suficientes em seu conjunto, que a ordem correta poderá ser estabelecida finalmente. (p. 108).

Pode-se denominar Jogo da Senha a qualquer jogo combinado entre pelo menos dois indivíduos (ou entre um indivíduo e uma máquina) em que um desafiador esconde determinado arranjo de símbolos (letras, números, figuras, quantidades etc.) para que o outro o descubra, logicamente mediante as informações recebidas do desafiante após a conclusão de cada jogada, o que dá ao jogo características de um processo de dedução ou de inferência.

As modalidades de Jogo da Senha utilizadas no estudo de caso que apresentaremos são muito semelhantes às do estudo de Piaget. O participante em questão jogou três modalidades, sendo P3 e P4, modelos em papel impresso e T4, instrumento industrializado. A planilha "Jogo da Senha três sinais" (Figura 1, anexo 1), doravante denominada P3, é impressa em folha de papel branco, formato A4 (dimensões $21 \mathrm{~cm} \times 29,7 \mathrm{~cm}$ ), com dez matrizes de uma linha por três colunas, perfazendo um total de três células, com dimen- 
Quadro 1. Tipificação de erros nas modalidades P3, P4 e T4.

\begin{tabular}{|c|c|}
\hline $\begin{array}{c}\text { TIPO DE } \\
\text { ERRO }\end{array}$ & \multicolumn{1}{c|}{ DESCRIÇÃo } \\
\hline E1 & $\begin{array}{l}\text { havia pelo menos uma informação de posição correta em jogadas anteriores que não } \\
\text { foi aproveitada na jogada atual, considerando-se apenas os resultados de uma mesma } \\
\text { partida. }\end{array}$ \\
\hline E2 & $\begin{array}{l}\text { caso tenha ocorrido na jogada atual utilização de maior número de variáveis que o } \\
\text { possível, ou conservação de posições incorretas. Tudo em função dos resultados obtidos } \\
\text { em jogadas anteriores da mesma partida. }\end{array}$ \\
\hline
\end{tabular}

sões individuais de $01 \times 01 \mathrm{~cm}$. Ao lado dessas matrizes de três células, está outra matriz de célula única, com a inscrição "posições corretas" marcando o lugar onde, evidentemente, registra-se o número de posições corretas em cada jogada efetuada. Nesses sistemas utilizados, chamaremos de partida uma sequência de até dez jogadas ou arranjos elaborados sequencialmente pelos indivíduos numa mesma planilha "jogo da senha"; uma jogada (ou arranjo) constitui o preenchimento de uma matriz com a mesma quantidade dos sinais (letras) A, B, e C. Observa-se que todas as linhas das matrizes estão numeradas sequencialmente e que existem espaços apropriados para anotarmos o nome, a idade, o sexo, o período que o estudante está cursando, a data de aplicação do jogo, o número sequencial de cada partida e o nome do examinador.

A planilha "Jogo da Senha - 04 sinais" (Figura 2, anexo 2), doravante denominada $P 4$, é semelhante a de três sinais, alterando-se simplesmente o número de células que, evidentemente, passa a ser de quatro unidades, demarcando os espaços para as jogadas em que, nesta modalidade, serão utilizados quatro sinais (letras A, B, C e D). A complexidade aumenta em função do maior número de permutações possíveis determinado pela adição de mais uma variável, a letra $D$.

Nas Figuras $1 \mathrm{~A}$ e $2 \mathrm{~A}$ (anexo 3 ), temos as planilhas "Senha Indicada - 03 (e 04) sinais", dispostas em folha de papel formato A4 (dimensões $21 \mathrm{~cm} \times 29,7 \mathrm{~cm}$ ), dez matrizes de uma linha por três (ou quatro) colunas, perfazendo um total de três (ou quatro) células com dimensões individuais de $01 \times 01 \mathrm{~cm}$. Estas matrizes são numeradas sequencialmente de 01 a 10, servindo, portanto, para marcar até dez partidas de uma mesma sessão.

A modalidade do jogo da senha 04 sinais industrializada (T4) é mostrada no anexo 4, foto do original MasterMind $\AA^{4}$. É composta por um tabuleiro de material plástico, pinos maiores em seis cores diferentes (azul, amarelo, vermelho, verde, laranja e branco) e pinos menores em duas cores (vermelho e branco). O tabuleiro possui: furos maiores, ordenados de quatro em quatro, feitos para suportarem os pinos maiores, e que servem para o jogador tentar reproduzir a senha escondida no anteparo localizado

$4{ }^{\circledR}$ MasterMind é marca registrada. na extremidade do mesmo tabuleiro; furos menores agrupados em quatro, que servem para o desafiante transmitir ao jogador o resultado de cada jogada efetuada; furos menores agrupados em dois e que servem para a marcação dos pontos alcançados em cada partida; depósito para guarda dos pinos e anteparo rebatível para esconder a senha. $O$ funcionamento do jogo também deverá ser explicado mais adiante no item "Procedimento geral de pesquisa".

No Método Clínico, exige-se do pesquisador uma atitude de interação para com o indivíduo, procurando compreender os passos de suas ações, formulando e testando hipóteses que podem (e que devem) surgir no momento da intervenção. Isso requer do pesquisador um conhecimento prévio de alguns modelos de solução para os problemas propostos, assim como de possíveis erros que aparecem em decorrência das ações dos indivíduos. O Quadro 1, descreve os dois tipos de erros investigados durante as partidas, nas modalidades $\mathrm{P} 3, \mathrm{P} 4 \mathrm{e}$ T4.

Um exemplo da análise dos erros do Jogo da Senha pode ser verificada por meio do registro das jogadas de Lúcio (nome fictício), com nove anos na época da pesquisa. Após os primeiros contatos com a modalidade T3, ainda reunido com todo o grupo, Lúcio passou a se recusar a jogá-la. Dizia que era muito fácil, que só servia para os outros dois participantes (Rebeca e Ivo) e que queria as modalidades mais difíceis (segundo o seu julgamento, T4, P4 e P3). Suas certezas provisórias rapidamente transformaram-se em hipóteses de jogo e, com isso, cresceram suas preocupações em verificar possibilidades. Porém, aos primeiros indícios de 'ferimentos' em suas certezas (em uma partida na modalidade T4), pareceu experimentar uma espécie de impossibilidade de julgamento que o fez ameaçar abandonar o jogo, o que efetivamente ocorreu após certa relutância.

$\mathrm{O}$ aspecto que mais chamava atenção em Lúcio era justamente essa aparente certeza de tudo, aparente superioridade, esse "não dar o braço a torcer". Isso contribuiu para a impressão imediata que se podia ter dele. Ele aparentava ser mais velho, mais esperto, mais forte, mais inteligente e mais seguro do que sua idade permite. Mas bastava estudar o seu real desempenho num jogo como este para se verificar que, tal como na vida, o seu padrão de condutas mostrava muitas oscilações. 


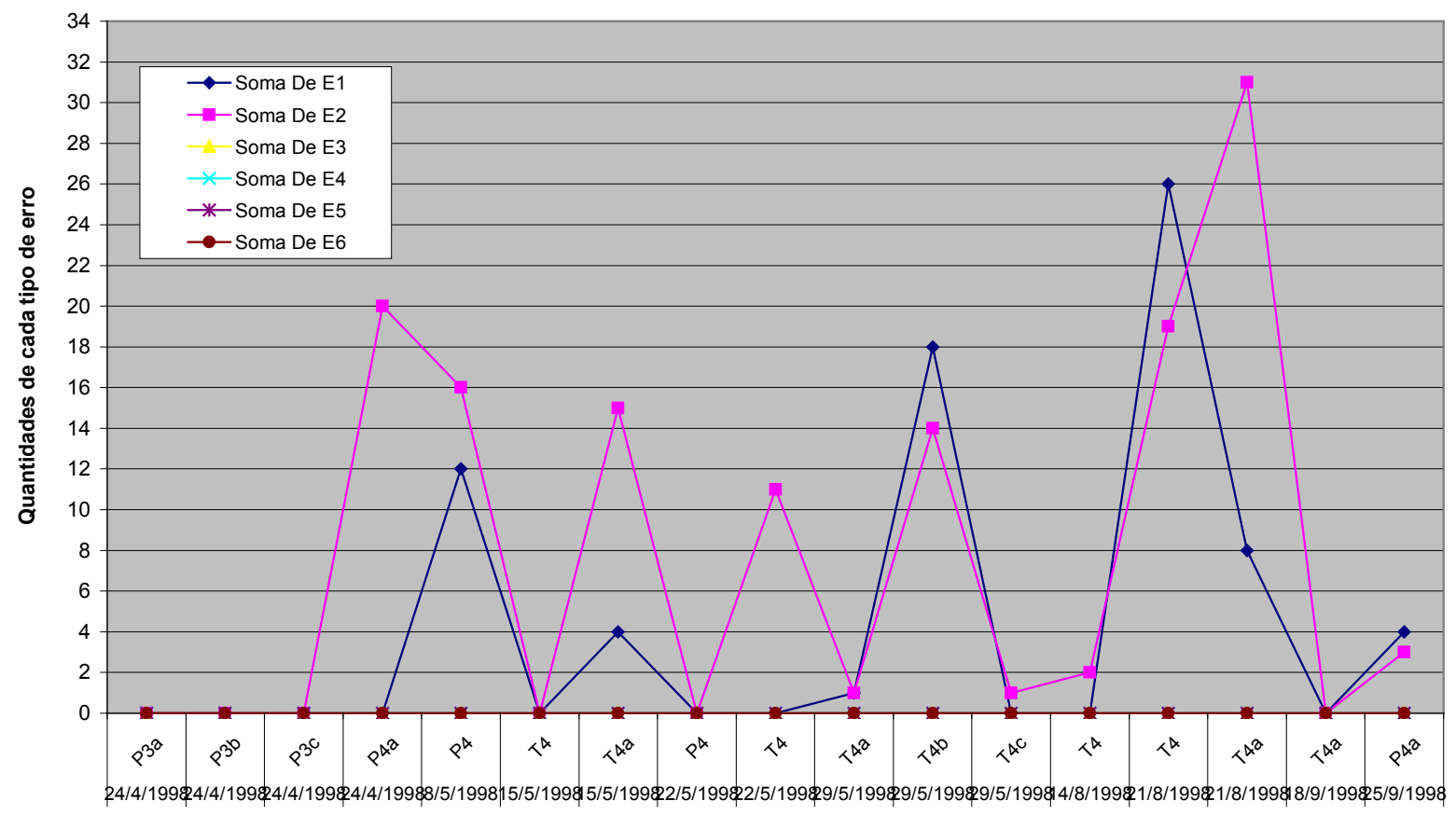

Instrumentos e datas dos eventos

O Gráfico 1, da distribuição de erros de Lúcio, embora resumido aos parâmetros E1 e E2 (porque nas modalidade em que jogou existia apenas essas possibilidades de erros), mostra que, quase o tempo todo, os níveis de erros que comete mantêm-se em patamares muito elevados. Muitíssimo curioso é o fato de que, em suas maiores 'crises de incertezas', o número de erros cometidos é nulo ou muito baixo. Evidentemente, tal constatação inibiria uma provável hipótese de que os erros denunciariam a emergência de um comportamento afetivo, digamos, inibidor do pensamento lógico. Ao contrário, até o momento, apenas podemos dizer que não há relação entre quantidades elevadas de erros e prejuízo ao desempenho baseado em raciocínio lógico.

É muito importante que os níveis 'inferiores' de características predominantes, no caso de Lúcio, apareçam como mínimos. Isso (aqui vivamente presente nesse estudo de caso) contribui para que se afaste de vez um pensamento unilateral acerca de dificuldades no âmbito do pensamento decorrentes apenas de um mal versar do raciocínio lógico. Ou, dito de forma mais clara: Lúcio apresentava problemas sobre os quais não podemos dizer o quê ou o quanto são afetivos, mas que, certamente, não eram puramente cognitivos. Talvez isso possa contribuir para confirmar (no plano empírico) a premissa básica de Piaget na teoria das regulações, segundo a qual afeto e cognição são inseparáveis.

\section{Considerações finais}

Este estudo considera o erro como produto da história do indivíduo ativo e construtor, e que traz, em seu apare- cimento (como erro procedimental ou sistemático), algo que ele necessariamente precisa fazer aparecer em suas ações sob a forma de um problema a ser resolvido e transposto. Piaget (1976), Inhelder, García e Vonèche (s/d) classificam três tipos de condutas - alfa, beta e gama - relacionadas às modificações e compensações efetuadas pelo sujeito em seu sistema cognitivo. As condutas do tipo alfa consistem em ensaios de neutralização da perturbação, suprimindo-a ou mesmo negando-a implicitamente por uma espécie de ignorância voluntária comparável a um recalcamento. As condutas beta são aquelas em que o sujeito considera esses fatores componentes de condutas alfa, porém procura compromissos que impliquem "deslocamentos do equilíbrio" do sistema inicial. Já as condutas gama caracterizam-se pela incorporação da perturbação mesma no próprio sistema; um retorno de fato, só que como "variação intrínseca" e dedutível do mesmo sistema.

Foi possível verificar que, em relação às condutas adotadas pelo participante Lúcio na interação com a tarefa, as duas únicas ocorrências de condutas alfa aconteceram exatamente em presença da grande dificuldade de lidar com o que julgava ser adversidade e o fazem abandonar o jogo. A predominância de condutas de tipo beta ocorre desde o início, e a sequência por elas formadas não é alterada por condutas alfa. Ou, melhor dizendo, excetuando-se a situação descrita anteriormente (que está longe de seu "padrão cognitivo"), Lúcio somente abandona condutas beta em prol das condutas gama. Podemos sugerir que essas reações indicam qualquer coisa que não construção cognitiva pura.

A Psicologia Genética não está, contudo, sozinha nessa difícil tarefa de investigar os erros nos processos de 
raciocínio ou no comportamento humano. A respeito disso, podemos citar duas de suas "companheiras de ciência" que tratam da mesma questão em muitos pontos de suas teorias. Sob duas perspectivas muito diferentes, o fazem a Neuropsicologia e a Psicanálise. A importância da primeira pode ser traduzida pela obstinação dos seus seguidores em "explicar a forma como certas operações cognitivas e seus componentes estão relacionados com os sistemas neurais e seus componentes", tal como aponta Damásio (1996) em seu livro O erro de Descartes, no qual faz interessantes reflexões acerca do modo humano de pensar.

A Psicanálise, por sua vez, mostra uma visão de erro bastante peculiar, exclusiva, elaborada de uma maneira que o caracteriza como elaboração do inconsciente, nos conduzindo a pensar o erro sistemático (da forma como foi definida acima) como algo produzido, de fato, pelo sujeito, ainda que isto impeça temporalmente o exercício da ação cognitiva propriamente dita. Assim se constitui o que Freud (1901/1976, 1905/1976) pesquisou sobre as parapraxias e os chistes em suas relações com a vida cotidiana.

Valerá a pena indicar alguns pontos enfatizados por Damásio (1996) até pelo fato da Neurociência apoiar-se em paradigmas muito novos em termos de estudos das funções cerebrais. Alertamos o leitor, no entanto, para que não tome estas notas como síntese ou resumo das ideias contidas no livro, posto que o desenvolvimento do mesmo é muito superior ao que aqui indicamos.

Por meio de relatos de estudos de casos clínicos com portadores de deficiências resultantes de lesões cerebrais, ele examina várias hipóteses relativas aos "erros" que estes pacientes passam a apresentar em relação às condutas que sempre Ihes foram usuais. Damásio acredita no sentimento como alguma coisa tão cognitiva quanto qualquer outra percepção; atribui exclusivamente ao ser humano a capacidade de planejar o futuro enquanto ser social, função dependente dos processos de tomada de decisão. Precisamente aqui reside a relação com o erro que é estabelecida pela Neuropsicologia: é fadado ao sujeito que aprenda mediante a percepção dos seus erros. Nos casos relatados por Damásio, os lesionados que mantêm intatos os seus conhecimentos, mas que não conseguem sequer perceber alterações fisiológicas simples, como o calor de uma chama que se aproxima do seu corpo, por exemplo, ou que não demonstram sentimentos de tristeza, ficam impossibilitados de utilizar esses conhecimentos em direção a processos de tomada de decisão. Isso ocorreu muitas vezes em virtude da "frieza" de raciocínio que interferia na atribuição de valores aos acontecimentos e, consequentemente, no julgamento dos mesmos.

O mais interessante é o fato de que, também por um estudo que se fundamenta na Neurobiologia, podemos constatar a impossibilidade de permanecer completamente no pensamento cartesiano, pelo menos no que diz respeito ao erro, sobretudo aquele que parece demonstrar certo impedimento do sujeito em ir adiante - o erro sistemático na nossa "linguagem genética". Mais uma vez, não se trata apenas de uma questão estrutural delimitadora daquilo que o sujeito pode ou não pode fazer. Aspectos funcionais do erro também precisam ser levados em conta nas análises, observações e entendimentos. Sobre isso, não podemos esquecer que temos sido advertidos pelos paradigmas agora em questão: os da Psicologia Genética, da Psicanálise, da Neuropsicologia e da Neurobiologia.

\section{Referências}

Casávola, H. M. (1988). O papel construtivo dos erros na aquisição dos conhecimentos. Em J. A. Castorina, Psicologia Genética: aspectos metodológicos e implicações pedagógicas. Porto Alegre: Artes Médicas.

Correia, C. E. F. (2005). Aprender com erros. EDUC@ação, 01(03).

Cury, H. N. (2004). Análise de erros em Educação Matemática. Veritati, 3(4), 95-107.

Damásio, A. R. (1996). O erro de Descartes (D. Vicente e G. Segurado, Trad.). São Paulo: Companhia das Letras.

Davis, C., \& Espósito, Y. L. (1990). Papel e função do erro na avaliação escolar. Cadernos de pesquisa, (74), 71-75.

Davis, C., \& Espósito, Y. L. (1998). Algumas considerações Sobre a teoria psicogenética na escola. Ideias, 8,127-132.

Freud, S. (1976). A Psicopatologia da vida cotidiana (Vol. VI). Edição Standard Brasileira das Obras Psicológicas Completas. (J. Salomão, Trad.). Rio de Janeiro: Imago. (Texto original publicado em 1901)

Freud, S. (1976). Os chistes e sua relação com o inconsciente (Vol. VIII). Edição Standard Brasileira das Obras Psicológicas Completas. (J. Salomão, Trad.). Rio de Janeiro: Imago. (Texto original publicado em 1905)

Inhelder, B., García, R., \& Vonèche, J. (s/d). Epistemologia Genética e equilibração. Lisboa: Horizonte Universitário.

Kistemann Jr., M. A. K. (2004). O erro e a tarefa avaliativa em Matemática: uma abordagem qualitativa. Dissertação de Mestrado, Universidade Federal do Rio de Janeiro, Rio de Janeiro.

Macedo, L. (1994). Para uma visão construtivista do erro no contexto escolar. Em L. Macedo, Ensaios construtivistas. São Paulo: Casa do Psicólogo.

Macedo, L. e cols. (2003). Avaliação do desempenho de crianças e intervenção em um jogo de senha. Psicologia Escolar e Educacional, 7(2), 185-195.

Piaget, J. (1976). A equilibração das estruturas cognitivas: problema central do desenvolvimento (M. M. dos S. Penna, Trad.). Rio de Janeiro: Zahar Editores. 
Piaget, J. (1978). Problemas de Psicologia Genética. Em J. Piaget, Os pensadores. Tradução de Célia E. A. Di Piero. São Paulo: Abril Cultural.

Piaget, J. (1986). O possível e o necessário 2: evolução dos necessários na criança (B. Machado, Trad.). Porto Alegre: Artes Médicas.

Piaget, J., \& Inhelder, B. (1979). Memória e Inteligência (A. R. Salles, Trad.). Rio de Janeiro: Artenova.

Queiroz, S. S. de. (1995). Tipificação de erros em um jogo de regras: uma abordagem construtivista. Dissertação de Mestrado, Universidade Federal do Espírito Santo, Vitória, Espírito Santo.
Queiroz, S. S. de. (2000). Inteligência e afetividade na dialética de Jean Piaget - um estudo com o Jogo da Senha. Tese de Doutorado. Universidade de São Paulo, São Paulo-SP.

Ribeiro, M. P. O. (2001). Funcionamento cognitivo de crianças com queixas de aprendizagem: jogando e aprendendo a jogar. Tese de Doutorado, Universidade de São Paulo, São Paulo, São Paulo.

Sisto, F. F. (1996). Contribuições do Construtivismo à Psicopedagogia. Em F. F. Sisto \& cols. (Orgs.), Atuação psicopedagógica e aprendizagem escolar. Petrópolis, RJ: Vozes.

Vinh-Bang. (1990). L'intervention psychopédagogique. Archives de Psychologie, (58), 123-135.

\section{Sobre os autores}

Recebido em: 27/05/2010

Reformulado em: 23/08/2011

Aprovado em: 06/09/2011

Prof. Dr. Sávio Silveira de Queiroz (savioqueiroz@terra.com.br)

Professor Associado - Departamento de Psicologia Social e do Desenvolvimento - Programa de Pós-Graduação em Psicologia da Universidade Federal do Espírito Santo.

Rua Constante Sodré, 1077/ 803 - Praia do Canto, Vitória-ES, CEP 29055-420.- Telefones: 33155842 / 81348960 / 40092505 / 40092501

Letícia Pires Dias (leticiapdias@yahoo.com.br)

Graduada em Psicologia pela Universidade Federal do Espírito Santo (UFES), Mestre em Educação na área de Psicologia, Desenvolvimento Humano e Educação, pela Universidade Estadual de Campinas (UNICAMP).

Rua Saul Navarro, 205/102, Praia do Canto, Vitória-ES, CEP: 29055-360.

Josana Deriz Chagas (josanachagas@gmail.com)

Graduada em Psicologia pela Universidade Federal do Espírito Santo (UFES).

Rua Raulino Rocha, 225, Morada de Camburi, Vitória - ES, CEP: 29062500.

Patrícia dos Santos Nepomoceno (patriciabragasantos@hotmail.com)

Graduada em Psicologia pela Universidade Federal do Espírito Santo (UFES).

Rua Carlos Eduardo Monteiro de Lemos, 190/205, Jardim da Penha, Vitória-ES, CEP: 29060-120.

Apresentado no VI Congresso Brasileiro de Psicologia do Desenvolvimento.

Trabalho derivado da Tese de Doutorado: QUEIROZ, S.S. Inteligência e afetividade na dialética de Jean Piaget - um estudo com o Jogo de Senha. São Paulo: USP, 2000. CAPES/PICD 